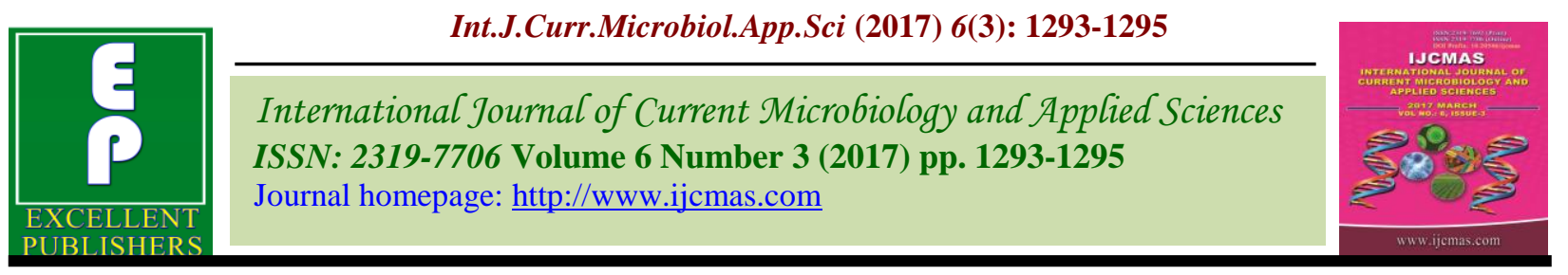

Original Research Article

https://doi.org/10.20546/ijcmas.2017.603.149

\title{
Seroprevalence of HIV, HBV, HCV and VDRL among Voluntary Donors in a Tertiary Care Hospital
}

\author{
K. Vijaya ${ }^{1}$, R. Shyamala ${ }^{2}$ and A. Durga Prasad ${ }^{3}$ \\ ${ }^{1}$ Department of Pathology, Mallareddy Medical College for Women, \\ Hyderabad, Telangana, India \\ ${ }^{2}$ Department of Microbiology, Mallareddy Medical College for Women, \\ Hyderabad, Telangana, India \\ ${ }^{3}$ Department of Anaesthesia, Mallareddy Medical College for Women, \\ Hyderabad, Telangana, India \\ *Corresponding author
}

A B S T R A C T

Ke y w ords

Transfusion

transmitted infections,

Seroprevalence,

Human

Immunodeficiency

Virus, Hepatitis C

Virus, Hepatitis B

Virus.

Article Info

Accepted:

20 February 2017

Available Online:

10 March 2017
This is a retrospective study to know the seroprevalence of HIV, HBV, HCV, Syphilis and malaria among voluntary donors in a tertiary care hospital. This study helps in increasing the awareness among clinicians about transfusion transmitted infections. A total of 7836 blood donors were screened during a period from June 2013 to December 2016, at Malla Reddy Medical College for Women, Jeedimetla, Hyderabad, Telangana state. Among 7836 donors, 6660 (85\%) were replacement donors and $1176(15 \%)$ were voluntary donors. Seropositivity for HIV was $(0.5 \%)$, HBV (1.2\%), HCV (0.85\%) Rapid Plasma Reagin method for syphilis and thick smear examination for malaria were negative in all the donors. Our study showed that there is a gradual increase in the Transfusion Transmitted infections in blood donors in our region.

\section{Introduction}

Although blood transfusion has been proven to be treatment of choice to save the patients with hemolytic anemia, post partum hemorrhage, surgical patients, accident cases and DIC, there is a $1 \%$ chance of Transfusion Transmitted Infections in them. It is mandatory to screen all donors for these diseases (Jasmin et al., 2012) as they can also occur without any symptoms. Transfusion of infected blood leads to mortality and morbidity and to consequences for the patients and their families, communities and ultimately to the society (WHO). Modern day Transfusion Medicine's biggest challenge is prevention of TTIs (Srikrishna et al., 1999). The diseases which are transmitted by blood transfusion are HIV, HCV, HBV, Syphilis, Malaria, and in minority of cases Cytomegalovirus, Epstein Bar Virus, Parvo Virus, Brucellosis etc. As per the guidelines of ministry of Health, and Family Welfare (Government of India) under the Drugs and 
cosmetics act 1945, all blood donors must be screened for five major infections -HIV1 and 2, HBV, Syphilis, and Malaria. With the advent of improved technological methods for detecting these diseases, strict donor screening and testing practices, the goal for safe blood free from TTIs seems achievable in near future. There are problems which have to be overcome -false negative results as the patient is in window period, asymptomatic carriers, technical errors, and emergence of highly variable genetic strains of the viruses (Gangadeep et al., 2010). The present study was undertaken to assess the prevalence of TTIs among the voluntary and replacement blood donors in our hospital blood bank and compare it with other studies.

\section{Materials and Methods}

This study was carried out in the blood bank of Mallareddy medical college for women Suraram, Jeedimetla, Hyderabad, Telangana. 7836 donors were analyzed for prevalence of TTIs, from June 2013 to December 2016. There were 6660 replacement donors and
1176 voluntary donors. A detailed pre donation questionnaire was included in the donor registration form. Information regarding occupation, previous surgery, hospitalization, blood transfusion tattoo marks and high risk behaviour was obtained. All the samples were screened for HIV, HCV HBV (ELISA and Rapid test,), RPR for syphilis and malaria by thick smear for both $P$. Vivax and $P$. Falciparum. All these tests were done as per the instructions of commercially available kits in the blood bank in the department of Pathology, Mallareddy medical college for women. The blood which was found to be positive for any of the TTIs was discarded immediately.

\section{Results and Discussion}

7836 donors were screened in a period of two and half years. The number of donations decreased in 2014, but increased in 2016 (Table 1). Table 2 shows the results of seropositive samples for HIV, HBV and $\mathrm{HCV}$.

Table.1 Year wise incidence of blood donors

\begin{tabular}{|l|l|l|}
\hline Year & Donors & $\%$ \\
\hline 2013 & 1240 & 1.58 \\
\hline 2014 & 2187 & 2.79 \\
\hline 2015 & 1948 & 1.48 \\
\hline 2016 & 2461 & 3.14 \\
\hline Total & 7836 & \\
\hline
\end{tabular}

Table.2 Seropositivity for HIV, HBV and HCV among the donors

\begin{tabular}{|l|l|l|l|}
\hline TTI & HIV & HBV & HCV \\
\hline 2013 & 3 & 25 & 16 \\
\hline 2014 & 8 & 30 & 20 \\
\hline 2015 & 16 & 18 & 14 \\
\hline 2016 & 13 & 22 & 16 \\
\hline TOTAL & $40(0.5 \%)$ & $95(1.2 \%)$ & $66(0.85 \%)$ \\
\hline
\end{tabular}


The major threat for blood transfusion is TTIs. With every unit of blood transfused there is $1 \%$ possibility of transfusion associated risk including TTIs (Garg et al., 2001) Professional donors, and those with high risk behaviour such as drug addicts, homosexuals and prostitutes constitute the major risk segment. The HIV Seroprevalence is between $0.2 \%$ to $1 \%$ in India (Sharma et al., 2004), the seroprevalence of HIV in our study was $0.5 \%$ which is similar to the National data. The prevalence of HBV in our study is $1.2 \%$, which is similar to a study done by Choudary et al., (2001). HBV prevalence ranges between $2 \%$ to $8 \%$ in different geographical areas of India. The reason for high prevalence of HBV may be due to reuse of needles by quacks and tattoing, and low socioeconomic status combined with illiteracy. It is a major source of transfusion transmitted hepatitis and is associated with carrier rate, chronic liver disease and Hepatocellular carcinoma.

Prevalence of HCV in our study was $0.85 \%$, which is high when compared to other studies which gave a prevalence rate of $0.26 \%$ to $0.35 \%$. In a similar study done by Chetna et al., (2013) in Rajasthan the seroprevalence of HIV, HBV, HCV was $0.034 \%, 1.57 \%$ and $0.04 \%$ respectively. Sensitive and specific tests like Nuclear amplification testing(NAT) for HCV, HIV, antihepatitis core antigen (HBcAg) and Ig M for Hepatitis B infection helps in identification during window period.

In conclusion implementation of strict criteria for donor selection as per the guidelines layed down by government of India for blood banks, use of sensitive and specific laboratory tests for screening the blood can improve the blood product safety and help in decreasing the occurrence of Transfusion Transmitted Diseases.

\section{References}

Chetna Jain, N.C., Mogra, Jhaman Mehta, Rishi Diwan, Gaurav Dalela. 2013. Comparison of Seropositivity of HIV, HBV, HCV, syphilis and malaria in Replacement and voluntary Blood Donors in Western India. Int. J. Curr. Res. Rev., Vol 05(03): 43-46.

Choudhary, N., Phadke, S. 2001. Transfusion transmitted diseases. Indian J. Paediatrics, 68: 951-958.

Gangadeep Kaur, Sabitha Basu, Ravneet Kaur. 2010. Patterns of infections among blood donors in a tertiary care centre, a retrospective study. The National Med. J. India, Vol 23, No3.

Garg, S., Mathur, D.R., Garg, D.K. 2001. Comparison of Seropositivity of HIV, HBV, HCV and syphilis in replacement and voluntary donors in Western India. Indian J. Pathol. Microbiol., 44: 409-412.

Jasmin Jasani, Vaidehi Patel, Kashik Bhuva, Anand Vachhavi. 2012. Seroprevalence of Transfusion transmissible infections among blood donors in a tertiary care hospital, Int. J. Biol. Med. Res., 3(1): 1423-1425.

Sharma, R.R., Cheema, R., Vajpayee, M., Raou Kumar, Marwaha, N., et al. 2004. Prevalence of markers of Transfusion transmitted diseases in voluntary and replacement donors. National Med. J. India, 17: 19-21.

Srikrishna, A., Sitalaxmi, S., Prema Damodar, S. 1999. How safe are our donors? Indian J. Pathol. Microbiol., 42: 411-416.

\section{How to cite this article:}

Vijaya, K., R. Shyamala and Durga Prasad, A. 2017. Seroprevalence of HIV, HBV, HCV and VDRL among Voluntary Donors in a Tertiary Care Hospital. Int.J.Curr.Microbiol.App.Sci. 6(3): 1293-1295. doi: https://doi.org/10.20546/ijcmas.2017.603.149 